\title{
Investigating, identifying and evaluating organizational and infrastructural strategic factors affecting organizational management processes from the perspective of productivity
}

\section{management}

\author{
Ali Mosayeb Moradi ${ }^{*}$, Neda Ahmad Khan Beigi ${ }^{2}$ \\ Faculty of Management and Industrial Engineering, Islamic Azad University, Karaj, Iran ${ }^{1}$ \\ Faculty of Industrial Management and Engineering, Islamic Azad University, Qazvin, Iran ${ }^{2}$ \\ alimmoradi1991@gmail.com $^{l^{*}}, \underline{\text { neda_ahmadkhanbeigy@yahoo.com }}{ }^{2}$
}

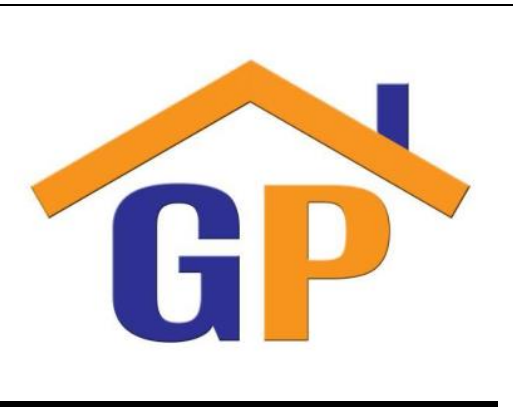

Article History

Received on 6 April 2021

Revised on 16 April 2021

Accepted on 20 April 2021

\begin{abstract}
Purpose: The purpose of this present study is to investigate the impact of institutional and infrastructural factors on knowledge management processes from the perspective of Nonaka and Takeuchi with a case study of design offices of a product organization.
\end{abstract}

Research methodology: The research is applied and is a descriptive survey in terms of data collection. The statistical population of the design offices of a product organization consisted of 75 people and the statistical sample was estimated 63 people. The research tool was a researcher-made questionnaire with a reliability of $77 \%$.

Results: The findings show that seven institutional and infrastructure factors affecting knowledge management processes were identified. Also prioritization by TOPSIS showed that organizational structure, culture and values, above average, can be deployed in the design office, and knowledge management policies and guidance are average, but information technology is below average.

Limitation: The results extend the understanding of the role of quality of work-life in organizational effectiveness. The research findings have implications for human resource managers.

Contribution: The results of the study help the human resource managers of organizations to identify the elements that affect the quality of work-life and help them in planning to increase organizational effectiveness by increasing employee satisfaction and motivation.

Keywords: Knowledge management, Institution, Infrastructure, Nonaka and Takeuchi

How to cite: Moradi, A. M., \& Beigi, N. A. K. (2020). Investigating, identifying and evaluating organizational and infrastructural strategic factors affecting organizational management processes from the perspective of productivity management. Annals of Management and Organization Research, $1(4), 285-305$.

\section{Introduction}

Generally, in recent years, the move towards knowledge-based societies has been a topic of debate everywhere. Human civilizations, too, from generation to generation, have been storing and transmitting knowledge to understand the past and predict the future. In today's complex and dynamic business 
environments, the thirst for knowledge grows ever wider and deeper; the knowledge that is changing drastically and spreading outside organizations (last, 2017). Nowadays, personal and organizational knowledge is one of the most important assets of any organization and its proper management will promote organizations in a comprehensive way. But the important issue before implementing a KM project is to identify the infrastructure and factors that affect the readiness of organizations to deploy KM.

Basically, knowledge management is the process of creating, storing, absorbing, disseminating and applying knowledge to enhance the productivity and effectiveness of an organization's activities. Although knowledge is mainly produced in humans, organizational knowledge, embedded in organizational routines and culture, plays a decisive role in promoting organizational performance and innovation alongside personal knowledge. Nowadays, knowledge management is considered as an appropriate competitive tool for success in the knowledge-based economy, so that many organizations have implemented and utilized knowledge management, but successful management deployment. Knowledge in the organization requires the availability of appropriate infrastructure factors in the organization. Therefore, using knowledge management in organizations reduces costs and improves the quality, productivity and profitability of the organization. A review of existing concepts and classifications in the field of knowledge management shows that there is a diverse range of views and perspectives in this field (Dubé, Bourhis, Jacob, \& Koohang, 2006).

Nowadays, despite geographical dispersal, organizations can collaborate with each other using new technologies through virtual groups and telecommunications. Knowledge management systems have the potential to be valuable to achieve these goals. Choosing the right tools and system for implementing $\mathrm{KM}$ is one of the managerial considerations, especially the institutional and infrastructure factors that make the use of open and hidden knowledge in organizations more beneficial. Therefore, the present study investigate the impact of institutional factors and knowledge management infrastructures on the organization's knowledge management deployment in design centers of a product-oriented organization (Dávideková \& Hvorecký, 2016).

\section{Problem statement}

Research shows that the most important characteristic of 21 st-century smart organizations is the emphasis on knowledge and information. Unlike in the past, today's organizations have advanced technology and require the acquisition, management and utilization of knowledge and information to improve the efficiency, management and pursuit of endless change. Knowledge is a powerful tool that can bring about change in the world and enable innovations. However, in this complex situation, taking advantage of all the benefits of KM in addition to spending time and money and investing properly requires the proper establishment of KM in the organization. Therefore, identifying and removing the barriers to deploying a KM project in the right way can lead to the benefit of $\mathrm{KM}$, otherwise resulting in a waste of resources, cost and time (and falling behind the competition for the organization). Design departments are dynamic institutions that have more dynamism and complexity if every approach and study of these institutions is the subject of their study.

In addition to the importance and complexity of looking at these types of offices, the type of management and planning patterns, organizational knowledge and learning will also vary. Undoubtedly, with a deep and scientific look at new organizations, it can be said that they have changed drastically based on two concepts of complexity and turbulence, and are very different from the past due to the time conditions in which they are located. So that the present nature of the world is based on discrete and fundamental changes. These changes have happened so fast and with so much competition that the great organizations of the twenty-first century are not able to withstand the emerging world of the 21 st century. Therefore, in these new environments, organizations need natural systems and their reflections to survive and succeed in order to be able to adapt quickly, recognizing changes in their organizations. Also, considering the importance of design offices in the country and their decisive role in the national economy and employment, it is necessary to seriously consider knowledge management in this sector and to examine the barriers to its establishment. 
Accordingly, this study aims to examine the effective infrastructures on knowledge management deployment and provide suggestions for improving its deployment in the organization. Because knowledge with its innovative and dynamic features enables it to respond to the characteristics of new environments, the importance of knowledge and its application in various domains in the organization and management is a key to success and to gain lasting competitive advantage. Research indicates that the implementation of a knowledge management system needs to identify the structural, institutional variables in the product-centric environments sector and determine its impact on product-centric results. Due to the nature of these variables in design offices, it can be said that the implementation of these variables has made the implementation of knowledge management better and more efficient and can utilize the benefits of full knowledge management in designing, developing, creating technology, reducing costs, project time and increasing quality of products used. The necessity and importance of reviewing, identifying, and evaluating the institutional and infrastructural factors affecting the knowledge management processes from the perspective of Nonaka and Takeuchi in the design offices of a product organization.

In the present study, the impact of institutional and infrastructure factors on knowledge management processes from the perspective of Nanaka and Takeuchi would be studied by a case study of design offices of a product organization. It is worth noting that today the rapid development of technology has led to activities to search for new ways, ideas and experiences to improve system and technology, process and product to drive this sector towards organizational innovation. For this reason, this office is transforming from pure production companies to knowledge-based companies (Nanaka and Takeuchi, 1996). In line with this move, understanding the underlying driving factors affecting the capabilities of institutional and infrastructure agents is a key strategic and strategic task for companies to remain in this changing environment and market (Commoner, 2020).

\section{Literature review}

Here it is necessary to give a brief overview of the key elements of knowledge management infrastructure. Referring to different texts, different factors can be named that are knowledge management infrastructures. Stankosky and Murray (2006) identify organizational culture, organizational structure, information technology, leadership, and learning as the success factors of a knowledge management program. Holsapple and Joshi(2000) have divided the effective factors on knowledge management into three groups: management, environmental and resource factors. In this regard, Hassanali et al (2013) consider the successful implementation of KM in five factors: leadership, organizational culture, organizational structure, roles and responsibilities. But in summary, among the factors mentioned are the factors of organizational culture, values, organizational context and leadership as institutional factors and information technology resources and equipment including hardware, software and network as infrastructural factors play an essential role in the successful implementation of knowledge in organizations.

Organizational Culture Among the many challenges mentioned in implementing a knowledge management program, some barriers are fundamentally rooted in organizational culture. Knowledge in organizations is power, and the provision of knowledge by individuals can place them in vulnerable situations. If a person's job promotion and promotion in the organization is due to the knowledge he or she has, it is not necessary to share his or her job position with the organization. Therefore, it is important for employees to feel that their value and status are not only diminished but also enhanced by sharing their knowledge or expertise. This requires an open and encouraging organizational culture that acts as a knowledge management enabler.

Also, the successful implementation of any project requires full and comprehensive management and leadership support. Implementation of KM is no exception, and it can even be argued that because of the underlying organizational culture debate in knowledge management and the leadership role of the organization in this culture, they receive more support. Request. In other words, knowledge management requires effective leadership. A prerequisite for successful results in the implementation of the knowledge management process is that university management is motivated and forward- 
thinking, and is capable of providing highly active and innovative organizational processes, as well as contributing to knowledge development (Intezari, 2017).

Information technology acts as a powerful enabler and provides effective and sufficient tools for all aspects of knowledge management including disclosure, sharing and application of knowledge. IT capabilities for searching, indexing, archiving, and transferring information can greatly facilitate the collection, organization, classification, and dissemination of information. Technologies such as relational database management systems, document management systems, internet, intranet, search engines, performance support systems, decision support systems, e-mail, video conferencing, electronic bulletins and group News media can play a key role in knowledge management. However, information technology is not, in itself, the heart of knowledge management and does not create knowledge, but merely serves as a supporter.

It is also worth noting that today's development of societies has taken on an explosive and uncontrollable variety of scientific and technological dimensions so that the world is witnessing the discovery and invention of tools and devices every day, explaining the methods, structures and processes that Without their application, it is impossible to solve the problems of organizations, which means that human beings have to constantly equip themselves with new knowledge and technologies in order to meet the growing and new organizational problems. Thus, human beings may at the time have the knowledge and skills needed to deal with organizational phenomena, but tangible and accelerated changes in science will rapidly abolish their knowledge and skills, and reconstruct and renew their knowledge and experience in the field. Formal participation in informal training courses to make adjustments necessary. Information technology, for its numerous benefits in terms of time-saving, cost and high operating speed, increased accuracy, plays an important and strategic role in achieving the goals of e-government and on-time. Therefore, today's society is called the information society because the phenomenon of information and communication technology has rapidly influenced human desires and its adaptation to human needs has led to the start of a new age, the information age in human life. As compared to the developed countries in the field of information technology, Iran is not good and needs proper management and facilities

Johnson divides computer literacy into two cognitive and emotional parts, which include cognitive components of a computer, hardware and software diagnostics, working on a simple computer system, noting that the computer needs to start, How the computer helps with the decision-making process, knowing that the computer is capable of storing the program and information, knowing that the computer receives instructions from a program provided in the programming language.

He sees the ultimate reason for emphasizing the actions of educational centers to be proficient in technology, promoting justice. In a desirable world, he argues, all students and students must have access to the technological resources needed to support their personal and professional interests. In fact, technological advances frequently leave people with little opportunity, resources, wealth, or access to public facilities (Milakovich, 2012).

In principle, information technology can act as a powerful tool and provide effective and efficient tools for all aspects of knowledge management including knowledge acquisition, sharing and application. Create, organize, classify, and disseminate information. Technologies such as related database management systems, document management systems, internet, intranet, search engines, workflow tools, implementation support systems, decision support systems, data mining, data storage, E-mail, image conferencing, bulletin boards, newsgroups, and discussion boards can all play a key role in facilitating knowledge management.

Knowledge management is a systematic process to gain a competitive advantage or achieve organizational goals. Knowledge itself is usually embedded in documents, processes and criteria. Because knowledge is considered a competitive resource, knowledge acquisition organizations identify, implement, and share the knowledge management initiative and take advantage of knowledge assets. These initiatives are the result of modeling, business or reengineering, quality management and learning organizations. Berggren argues that knowledge management is an optimal and systematic strategy that 
is selected, organized and stored, and improves the essential business information of a company to enhance employee performance and enhance the competitiveness of the organization.

From Zafarian et al's viewpoints, knowledge management approaches can be identified in two ways. The first approach is based on the dimension of knowledge management systems, which encompasses a range of approaches, systems, and operational approaches designed to support and manage knowledge-based processes. According to this view, the knowledge management process relies heavily on information technology. The second approach is the social approach. The focus is on individuals and members of the organization. Because knowledge is believed to be a social phenomenon. According to this approach, a large part of the organization's knowledge is tacitly invisible and one of the concerns of this approach is the conversion of tacit knowledge into explicit knowledge.

In principle, knowledge management and related strategic concepts have been considered as important components of an organization's survival and maintaining its competitive position.. In addition, Martenson argues that knowledge management is a definite prerequisite for the productivity and flexibility of public and private organizations, and hence its focus on the duties and responsibilities of managers and officials. Organizations have found that technology-based competitive advantages are temporary and fleeting, and the only sustainable competitive advantage is their employees. Accordingly, organizations that adapt their structures for faster adaptation, better response, and foresight will become more learning organizations.

\subsection{Knowledge management}

In today's post-industrial society, intangible and spiritual assets called "knowledge" are seen as an important and vital factor. Knowledge has become a key source of progress and excellence in all fields. Successful implementation and implementation of knowledge management require the long-term support and guidance of senior management, leadership and guidance that is relevant to the culture of the organization, as well as the involvement and participation of trained staff and managers and the proper application of technology. This has drawn the attention of the industry and industry scholars to an enormous and valuable asset, a capital that is less managed, organized and planned despite producing the majority of value-added.

Basically, knowledge management involves the stages, production, acquisition, storage, dissemination, and application of knowledge for the purposes of the organization. Of course, this classification has been discussed in various ways in scientific sources. Because knowledge management encompasses all the ways that an organization manages its knowledge assets, including how to collect, store, transfer, apply, update and create knowledge.

From the point of view of the Brotherhood and the peasantry, the increase in the volume of information and knowledge and the need to use them effectively in decision-making have led to the phenomenon of knowledge management. In fact, organizations need to develop appropriate knowledge strategies for themselves to succeed. Because the only way to achieve sustainable competitive advantage in organizations is to make good use of intellectual capital.

Knowledge management as a new approach focuses on the need for the organization, which is the organization of intellectual, human and scientific capital, and is emerging as a new approach to changing and shifting from physical force management to brain management and growth. Rapidly it has given rise to science and technology. Because, according to the guidance document, assessing the readiness levels and maturity of design offices is generally appropriate for the knowledge-sharing infrastructure in the organization. Among the individual and organizational factors affecting knowledge sharing, insufficient time to participate in knowledge sharing activities has been an obstacle to this activity. The status of education, utilization of information technology and formal and informal activities in the organization in the field of knowledge sharing is relatively good; however, there is not a good situation regarding policies and strategies for institutionalizing knowledge sharing activities

Hoffman and her colleagues believe that knowledge management is the process of creating and sharing knowledge in a way that can be applied effectively in an organization. 
Gupta and others, on the other hand, use knowledge management as a process that helps the organization find, select, distribute and transfer the information and expertise needed for activities such as problemsolving, dynamic learning, strategic planning, and decision making. They define, they define

Meyer also considers knowledge management a systematic and integrated approach to identifying, utilizing, and sharing existing, systematic, and unbiased experiences in the organization. According to Meyer, knowledge management is a strategy to create, access, and support a critical source of knowledge.

From Siliv's perspective, knowledge management is the process of managing the intellectual capital of the organization.

Abtahi also considers knowledge management as the management and grounding of knowledge transfer within an organization through the acquisition, sharing and use of knowledge as human capital to achieve the goals of the organization. Abtahi quotes Blunt writes that knowledge management is the process by which organizations use their collected information.

In summary, some of what should be managed in the literature related to knowledge management are some of them including knowledge, management process, scholars, honesty-based human communication, information technology, knowledge culture Axis, flexible organizational structure, performance measurement tools and reward system. Explaining that all of the above is very difficult to manage. In addition, some of the above are not only extensive but also very complex to manage.

\subsection{Knowledge management goals}

- Creating value in organizations

One of the clear goals of knowledge management is to create value in organizations. One of the most popular ways of creating value for students is to support effective decision-making. Creating value does not necessarily mean creating economic value. Nonprofits, government agencies, and charities create value in a non-economic way. They create what is called social capital. Knowledge The knowledge that can make value decision-making effective is a prerequisite for knowledge management.

- Implicit knowledge management

The transformation of informal, mental, and personal (implicit) knowledge into formally registered knowledge is called explicit knowledge. This key goal is to reduce the risk of losing valuable knowledge of the organization by abandoning employee collaboration and reducing the risk of losing company memory when manpower adjustment.

The benefits of knowledge management also include reusing existing knowledge and avoiding the repetition of costs to solve repetitive problems. Knowledge management reduces the time period of problem expression to problem transparency and can accelerate marketing and help the organization through accurate marketing or customer needs recognition. The organization can also use the stored knowledge to solve a range of problems such as new product production, advertising planning, customer complaint handling, and more.

Knowledge management also increases internal efficiency, service coordination, and overall profitability. Organizational knowledge creates value by providing an improved environment for the development of new knowledge and the use of problem-solving experience. In addition, it can provide the ground for creativity and sustainable innovation and empower the organization to adapt to the environment and current conditions (Bigliardi \& Galati, 2013).

\subsection{Nonaka and Takeuchi models}

In general, more than 20 models of knowledge management have been proposed so far. Most of these models are almost identical in content but have different words and phrases. In these models, it is assumed that the steps and activities, often simultaneously, are sometimes sequential and rarely in a linear order. Among these models, the Nonaka and Takeuchi models are one of the best in terms of explaining how to produce knowledge. Therefore, this model has been selected to study the desired organization (design office). This model is the only model that covers all types of knowledge and clearly expresses the levels of knowledge and the level of their conversions to each other. In fact, the Nonaka 
and Takeuchi models can use and localize to create a knowledge management process. Unlike other models, this model focuses on two types of overt and covert knowledge and focuses on how to transform them into each other and how to create them at all organizational levels (individual, group and organizational).

It is worth mentioning that this theory of organizational knowledge production was proposed by Nonaka in 1994 and emphasizes the active and mental nature of knowledge and the correction of beliefs and people's participation. This theory considers the main function of the organization in strengthening the knowledge produced by individuals and crystallizing it as part of the knowledge network of the organization, and a year later it was manifested in the famous model of Nonaka and Takeuchi.

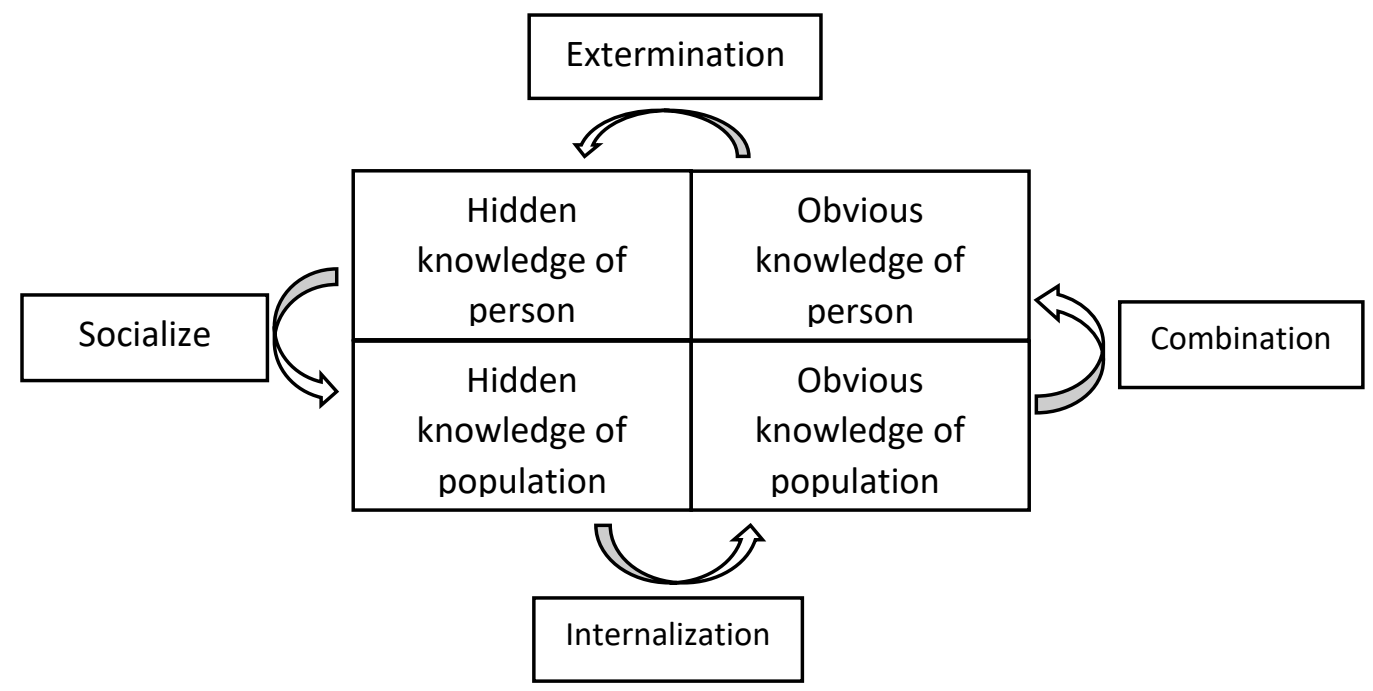

Figure 1. Nonaka and Takeuchi organizational knowledge model

The basis of this model is hidden knowledge, overt knowledge and their transfer processes. It is worth mentioning that the researchers of the Japanese management of Nonaka and Takeuchi (1996) have had a great impact on the basics of knowledge management. The concept of hidden knowledge and overt knowledge has been categorized by Nonaka for designing organizational learning theory. In this classification, given the convergence between the hidden and overt forms of knowledge, they have established a model known as their own. This model, unlike previous models, focuses on two types of overt and covert knowledge, how to convert them to each other and how to create it at all organizational levels (individual, group and organizational level) (Nonaka \& Konno, 1998).

\section{Socialize (hidden to hidden)}

Transmitting the intangible knowledge of one person to another (how to solve a program-design problem unusually). For this process to be effective, there must be a common culture and ability to work in groups. This is made possible by the use of social theories and collaboration. Meeting a group that explains and discusses experiences is a normal activity in which the sharing of hidden knowledge can take place.

\section{Extermination (hidden to obvious):}

Transforming invisible knowledge into obvious knowledge. In this case, one can present one's knowledge in the form of regular materials (seminars, workshops) to others. Conversations between a group, in response to questions or perceptions of events, are among the common activities in which this type of transformation occurs.

\section{Connection (obvious to obvious)}

At this stage, the shift from explicit individual knowledge to explicit group knowledge and its storage takes place, and due to the use of existing knowledge, the possibility of solving problems through the provided group, followed by that knowledge, is developed. 


\section{Internalization (obvious to hidden)}

At this stage, the obvious knowledge gained in the organization is institutionalized. Going through this stage for individuals also leads to the creation of new personal implicit knowledge (acquiring new hidden knowledge from existing obvious knowledge).

The above four steps must be followed continuously and in a spiral-like manner, so that each stage completes the previous stage and, while institutionalizing the knowledge in the organization, also causes the production and creation of new knowledge.

The creation of knowledge is the result of the interaction between individuals and overt and covert knowledge, through the interaction of the individual with others, covert, externalized knowledge is shared. By other employees, they create, disseminate, and internalize knowledge. Since all the processes of this model are important, it is necessary to consider them in the integrated knowledge management by considering the necessary measures and planning and also considering the position of the desired organization, to establish a balance between these processes.

Another important point is that when people participate in these processes, organizational training also takes place. Because people's knowledge is shared with others, it is explained and made available to others. Also, the creation and production of new knowledge occur through these processes. Of course, it should be noted that these processes do not occur in isolation, but occur in different combinations and in our work situations between people who work with each other. For example, the creation of knowledge is the result of the interaction of individuals and overt and covert knowledge. Through one's interaction with others, hidden knowledge is externalized and shared. In these processes, individuals create, disseminate, and internalize knowledge through knowledge management, while gaining insight and organizational experience, or through other employees.

One of the concerns of managers in any organization is the proper management of the knowledge resources of that organization. Especially nowadays, knowledge has been introduced as the key source of competitive advantage (Akhavan et al., 2011, Jafari et al., 2011). Organizations, by focusing on their knowledge resources, seek to become knowledge-based and, based on their growing needs, have put the production of key knowledge and the use of shortcuts on their agenda. Certainly, knowledge management in the subsets of each organization is subject to the conditions and requirements of the collection and it is not possible to draw a single pattern with all the details for them. In the following, we have tried to introduce some of the most important process patterns of knowledge management.

Allard, S., \& Holsapple (2002) list five main types of activities, including acquisition, selection, internalization, externalization, and generalization of knowledge, for knowledge management in the organization. In her opinion:

"In the ontology of knowledge management, there are five main types of knowledge activity. Knowledge can flow during these activities. The arrangement of these activities can be in different ways and the ways of doing it can be done through various processes." These main activities are:

$\checkmark$ Acquisition of knowledge: occurs when knowledge in an external environment for use within the organization has been identified and has not changed in any way (filtering, reconstruction, etc.).

$\checkmark$ Selection of knowledge: describes the identification and possibility of knowledge transformation among the main capital of knowledge within the organization.

$\checkmark$ Internalization of knowledge: The activity of acquiring knowledge that has been obtained and selected and distributed and stored within the organization.

$\checkmark$ Externalization of knowledge: The activity of knowledge penetration in outputs (products, services, etc.) to be released in the external environment.

$\checkmark$ Generalization of knowledge: Providing the production of new knowledge from existing knowledge can be a form of discovery or adaptation. 
Some authors have considered both public and business activities as the creation of knowledge. From Sugurmaran and Bose's (2003) perspective, the knowledge management framework includes four major processes that are described below. (Figure 2).

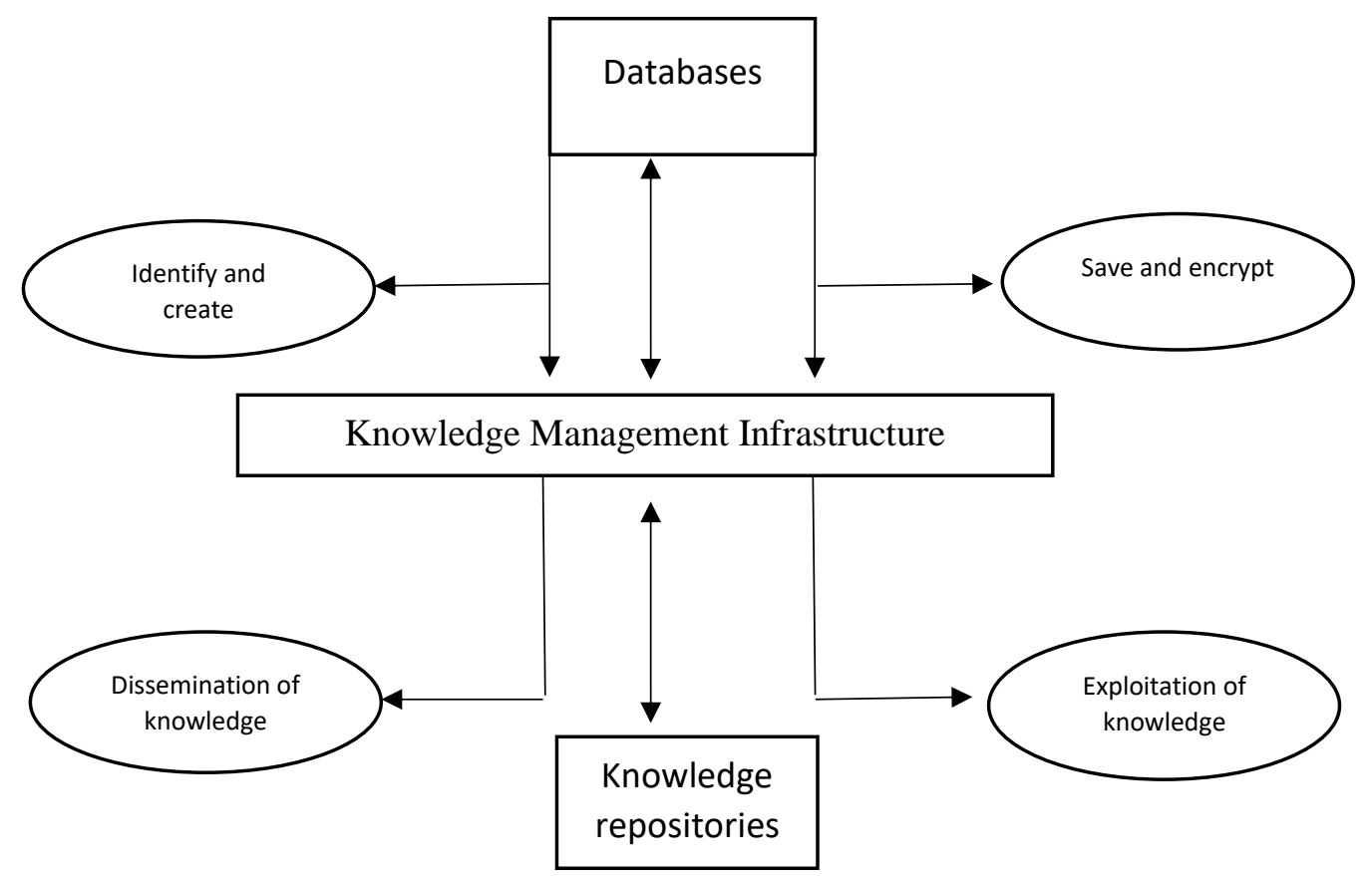

Figure 2. Fundamental Processes of Knowledge Management from the Perspective of Sugurmaran and Bose (2003)

Knowledge identification and production: Creating and creating knowledge refers to the organization's ability to create and create efficient and new solutions and ideas. By shaping and re-combining the new knowledge of the organization with the previous knowledge, the organization will be able to create new concepts and realities.

Knowledge storage and coding: This step involves converting knowledge into an understandable form for the machine for future use. In general, this step refers to documenting new knowledge and storing it so that all stakeholders can easily benefit from this knowledge.

Knowledge distribution and dissemination: Knowledge dissemination processes are related to the distribution of knowledge throughout the organization. At this stage, numerous and continuous interactions and connections between technology, techniques and skills of individuals are necessary for the organization to be able to expand knowledge effectively.

Utilization and feedback on knowledge: This step enables stakeholders and knowledge users to solve the problems of the organization using the created knowledge. Also, the use of knowledge to solve a particular problem or issue may lead to the production and creation of new knowledge that this knowledge will be re-stored and retrieved.

Williams and Bukowitz (2001) consider the knowledge management framework and its key activities to include seven steps:

1- Gaining knowledge: Achieving knowledge through various tools such as library resources, databases and scientific groups

2- Using knowledge: Using the acquired knowledge that has been recognized as useful and appropriate. 3- Learning: Teaching members of the organization about past experiences and the organization's support for learning and gaining experience by its members.

4- Sharing and exchanging knowledge: Organizational support for knowledge exchange between members and bilateral and multilateral interactions in this regard. 
5- Assessing knowledge: Creating a framework by the organization using quantitative and qualitative tools and criteria to assess the status of the organization's knowledge assets, management strengths and weaknesses and the effects of knowledge use in the organization.

6- Creating and consolidating knowledge: Gaining the organizational ability to create, produce and consolidate knowledge and use information technology tools to help perform tasks and use participation and cooperation as tools for knowledge consolidation.

7- Optimal use of knowledge: The organization, knowing the importance and amount of its knowledge assets and based on a planned and measured method, makes optimal use of knowledge and takes care of the existence of strategic and vital knowledge and people with this knowledge in the organization.

Williams and Bukowitz (2001) categorize knowledge management processes into strategic and tactical, including tactical aspects of acquiring, applying knowledge, learning, sharing, and sharing knowledge between individuals. Strategic processes are also considered to derive value from the tactical process. In another classification made by Gilbert Probst et al. (2003), six main activities were identified as the cornerstone of organizational knowledge management, which are:

$\checkmark$ Knowledge recognition;

$\checkmark$ Gain knowledge;

$\checkmark$ Knowledge development;

$\checkmark$ Sharing and distributing knowledge;

$\checkmark$ Exploitation of knowledge;

$\checkmark$ Keeping knowledge;

Proabst et al. (2003) show how to connect the above key elements in Figure 3:

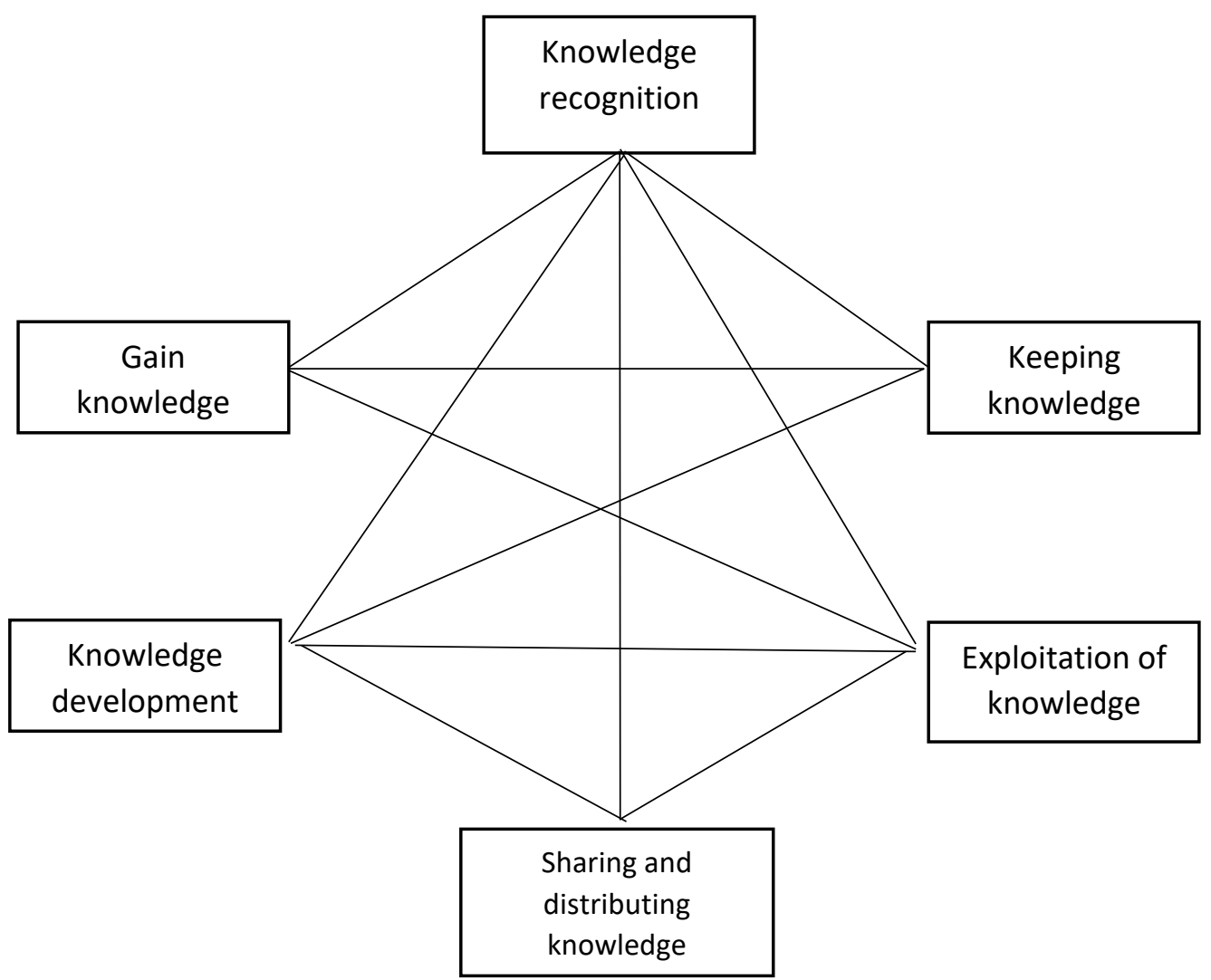

Figure 3. Six cornerstones of knowledge management from the perspective of Probst et al. (2003)

Table 1-1, which summarizes and summarizes the views of various scientists in the field of knowledge management (during the years 1993-1997), has well examined the various views on the key activities of knowledge management. 
The following is a summary of the knowledge management implementation process. the mentioned process has been prepared by the authors of the book by adapting the results and achievements of knowledge management projects and efforts have been made to consider the outlines of the contents and the most important topics according to the practical experiences of the authors for optimal implementation of the model.

Table 1. Key activities of knowledge management from the perspective of some researchers

\begin{tabular}{|c|c|}
\hline Key knowledge management activities & Author name \\
\hline $\begin{array}{l}\text { Giving knowledge (production and development of knowledge content), } \\
\text { identification, filtering, connecting the show, uploading, cataloging, } \\
\text { integrating and linking internal and external knowledge sources }\end{array}$ & $\underline{\text { Keenan et al.(2018) }}$ \\
\hline $\begin{array}{l}\text { Knowledge sharing, knowledge creation, knowledge identification, } \\
\text { knowledge collection, knowledge conversion, knowledge organization, } \\
\text { knowledge application }\end{array}$ & Sánchez et al.(2013) \\
\hline $\begin{array}{l}\text { Knowledge sharing, knowledge creation, knowledge identification, } \\
\text { knowledge collection, knowledge conversion, knowledge organization, } \\
\text { knowledge application }\end{array}$ & $\underline{\text { Intezari et al.(2017) }}$ \\
\hline $\begin{array}{c}\text { Acquiring knowledge, organizing, storing, storing, analyzing, creating } \\
\text { knowledge, displaying knowledge, distributing knowledge, applying } \\
\text { knowledge }\end{array}$ & $\underline{\operatorname{Argote}(2012)}$ \\
\hline $\begin{array}{l}\text { Creative and common solutions to problems } \\
\text { attractive and important technical knowledge outside the company } \\
\text { testing prototypes, applying and integrating methods and tools }\end{array}$ & $\underline{\text { Lewrick et al.(2018) }}$ \\
\hline $\begin{array}{l}\text { Socialization (converting tacit knowledge to tacit knowledge), } \\
\text { internalization (converting explicit knowledge to tacit knowledge), } \\
\text { combining (converting explicit knowledge to explicit knowledge), } \\
\text { externalizing (converting implicit knowledge into explicit knowledge) }\end{array}$ & Astorga et al.(2017) \\
\hline $\begin{array}{l}\text { Knowledge identification (recognition of required knowledge and its } \\
\text { fulfillment), knowledge implementation (knowledge transfer), knowledge } \\
\text { check (use of transferred knowledge), integration (internalization of } \\
\text { knowledge) }\end{array}$ & Dalkir(2017) \\
\hline $\begin{array}{l}\text { Knowledge development, knowledge distribution, knowledge } \\
\text { composition, knowledge retention }\end{array}$ & Verhagen et al.(2012) \\
\hline Creating knowledge, manipulating knowledge, exploiting, transmitting & Wiig(1997) \\
\hline Collect, refine, configure, publish, use & Powell et al(2015) \\
\hline $\begin{array}{l}\text { Acquisition of knowledge, selection of knowledge, internalization of } \\
\text { knowledge, production of knowledge, externalization of knowledge }\end{array}$ & Holsapple et al(2003) \\
\hline $\begin{array}{c}\text { Perspective on knowledge management, knowledge management goals, } \\
\text { knowledge management indicators }\end{array}$ & $\underline{\text { Girard(2015) }}$ \\
\hline $\begin{array}{c}\text { Preparing and providing infrastructure, knowledge recognition, knowledge } \\
\text { collection, organization, storage, knowledge sharing, and knowledge } \\
\text { management process evaluation }\end{array}$ & Akhavan et al. (2009) \\
\hline
\end{tabular}

\subsection{Background research}

In the following table, the factors resulting from the most important studies of the research background are mentioned in table 2 .

Table 2. Micro-factors derived from research background studies

\begin{tabular}{|c|c|c|c|}
\hline Source & Description & Institutional factors & Infrastructure factors \\
\hline$\underline{\text { Keenan et }}$ & $\begin{array}{c}\text { Investigating the } \\
\text { knowledge of } \\
\text { infrastructural factors } \\
\text { related to the } \\
\text { implementation of }\end{array}$ & $\begin{array}{c}\text { Organizational culture, } \\
\text { modeling }\end{array}$ & $\begin{array}{c}\text { Information systems, } \\
\text { knowledge structure }\end{array}$ \\
\hline
\end{tabular}




\begin{tabular}{|c|c|c|c|}
\hline & $\begin{array}{c}\text { knowledge } \\
\text { management in } \\
\text { Hekmat Iranian Bank }\end{array}$ & & \\
\hline$\frac{\text { Sánchez et }}{\underline{\text { al.(2013) }}}$ & $\begin{array}{c}\text { Study the } \\
\text { infrastructure needed } \\
\text { to implement } \\
\text { knowledge } \\
\text { management based on } \\
\text { the Nonaka and } \\
\text { Takeuchi models }\end{array}$ & - & $\begin{array}{c}\text { Organizational } \\
\text { information technology, } \\
\text { operational structure, } \\
\text { time, etc. }\end{array}$ \\
\hline$\frac{\text { Intezari et }}{\text { al.(2017) }}$ & $\begin{array}{c}\text { A Study of } \\
\text { Knowledge } \\
\text { Management Sub- } \\
\text { Problems } \\
\text { (Management Factor, } \\
\text { Organizational } \\
\text { Culture and Technical } \\
\text { Factors) in the Faculty } \\
\text { of Educational } \\
\text { Sciences, University } \\
\text { of Isfahan, from the } \\
\text { Perspective of Faculty } \\
\text { Members }\end{array}$ & Organizational Culture & $\begin{array}{l}\text { Management factor, } \\
\text { technical factors }\end{array}$ \\
\hline Argote(2012) & $\begin{array}{c}\text { Comparative } \\
\text { Knowledge } \\
\text { Management Title: A } \\
\text { Preliminary Study } \\
\text { between Chinese and } \\
\text { American Universities }\end{array}$ & - & $\begin{array}{c}\text { Functional knowledge, } \\
\text { technological tools and } \\
\text { knowledge management } \\
\text { management structure }\end{array}$ \\
\hline$\frac{\text { Lewrick et }}{\text { al.(2018) }}$ & $\begin{array}{l}\text { Examining different } \\
\text { organizations, it has } \\
\text { mentioned four } \\
\text { general categories of } \\
\text { hard and soft factors } \\
\text { that are effective in } \\
\text { implementing } \\
\text { knowledge } \\
\text { management. }\end{array}$ & $\begin{array}{l}\text { Product related factors, } \\
\text { Factors related to the } \\
\text { knowledge system }\end{array}$ & $\begin{array}{l}\text { Factors related to the } \\
\text { organization, factors } \\
\text { related to the } \\
\text { environment }\end{array}$ \\
\hline$\frac{\text { Astorga et }}{\text { al.(2017) }}$ & $\begin{array}{l}\text { Prioritization of key } \\
\text { infrastructure factors } \\
\text { in order to establish } \\
\text { knowledge } \\
\text { management system } \\
\text { in project } \\
\text { organizations } \\
\end{array}$ & $\begin{array}{l}\text { The mission and value of } \\
\text { the organization, the } \\
\text { organizational culture }\end{array}$ & $\begin{array}{l}\text { Organizational structure } \\
\text { and processes, } \\
\text { information technology }\end{array}$ \\
\hline Dalkir(2017) & $\begin{array}{l}\text { Investigate the } \\
\text { infrastructure needed } \\
\text { to establish } \\
\text { knowledge } \\
\text { management and } \\
\text { document knowledge } \\
\text { and experience }\end{array}$ & - & Network \\
\hline
\end{tabular}

\section{Research methodology}

Since the present study seeks to identify and influence the relationship between knowledge management and its effective infrastructure in the design offices of a product-oriented organization, so the present research is applied in terms of purpose and descriptive-survey in terms of method because Regularly deals with the characteristics of an organization. Also, since the data collection in this research is supported by library studies and questionnaires, it can be included in the field research group. In the present study, two types of questionnaires have been used to measure variables, one for measuring knowledge management components and the other for measuring knowledge management infrastructures. The standard questionnaire of knowledge management infrastructures consists of 42 questions that examine the status of institutional factors and knowledge management infrastructures consisting of seven dimensions of culture, value, leadership, organizational context, hardware, software 
and network. Statistical community according to the subject that examines the effect of institutional factors and knowledge management infrastructure on the establishment of knowledge management in the design offices of a product-oriented organization, which in terms of work experience and education and type of job sufficient diversity to select as research statistical community has it. The sample use of Morgan's table, among the statistical population of 75 people, is 63 people and sampling will be simple random sampling. The questionnaire is based on the Likert spectrum. To measure the reliability of the questionnaire, Cronbach's alpha method of SPSS software was used, the value of which was 0.77. Therefore, the questionnaire can be considered valid. Since all the items of the questionnaire used to measure these goals are based on previous studies and the questionnaire has been reviewed and verified by experts, it is possible to ensure the validity of its content. In the research model, the institutional and infrastructural factors of knowledge management with the approach of Nonaka and Takeuchi (1996) are considered. Therefore, the impact of institutional and infrastructural factors on the knowledge management process has been investigated.

\section{Research findings}

Knowledge management helps an organization to gain knowledge and insight from its experiences and focus its activities on acquiring, storing and using knowledge so that it can solve problems, dynamic education, strategic planning and decision making. Use this knowledge. Knowledge management not only prevents the decline of the organization's brain assets but also continuously increases this wealth. Today, knowledge is considered as one of the important strategic resources of organizations and the main engine of growth and wealth creation in organizations and more than other sources such as work and capital, it plays a role in development. Experts see knowledge as the ultimate alternative to production, wealth and monetary capital.

Based on the research and experts' opinion, 7 parameters have been considered as criteria for decision making, including leadership, organizational context, culture and value $\neg$ to the factors of inputs and software, hardware and hardware and topics. The network is the underlying factor, so the decision matrix will be created, and by normalizing the decision matrix, the weight matrix of the parameters can be obtained. SPSS statistical software, as well as the Topsis method, have been used to analyze the data and test the hypotheses.

The present questionnaire, which was designed concerning the research topic, has the characteristics of the male and female population, which includes the average age of 25 to 55 years. Their major is a bachelor's degree or higher. This questionnaire contains approximately 42 questions and 5 options. Using Morgan's table, 63 experts were selected. Using the expertise method, it will be made available to experts and specialists, and finally, after applying the opinions suggested by the experts, the components will be determined and classified. The score of the questionnaire is based on the five-point Likert scale and from very good to very poor.

In the SPSS software, the output of all questionnaires was extracted, which included the number of answers, percentages, as well as a cumulative percentage for all infrastructure and institutional indicators. Tables 3 are an example of the values of abundance, frequency, and cumulative percentage of parameters.

Table 3. Average frequency tables of organizational tissue index institutional responses

\begin{tabular}{|c|c|c|}
\hline Organizational texture & Abundance & Percent \\
\hline Very good & 17 & 27.2 \\
\hline good & 20 & $6 / 31$ \\
\hline medium & 11 & $5 / 17$ \\
\hline weak & 5 & $9 / 7$ \\
\hline Very weak & 10 & $8 / 15$ \\
\hline Total & 63 & 100 \\
\hline
\end{tabular}

The results of the analysis of Table 4 show, and the significance level of all factors is less than 0.05 . It is clear that there is a relationship between the institutional factor and all the factors among the personnel 
in this organization. Therefore, it can be said that the effect of factors on knowledge management processes is confirmed. The standard path coefficient also shows that the effectiveness of the institutional factor of values is $22 \%$.

Table 4. Regression test of the effect of the institutional factor of values on knowledge management

\begin{tabular}{|c|c|c|c|c|c|}
\hline $\begin{array}{c}\text { Significance } \\
\text { level }\end{array}$ & $\begin{array}{c}\text { Standard path } \\
\text { coefficient }\end{array}$ & $\begin{array}{c}\text { The standard } \\
\text { deviation }\end{array}$ & Average & $\begin{array}{c}\text { Institutional } \\
\text { agent }\end{array}$ & column \\
\hline $0 / 001$ & $0 / 221$ & $0 / 68$ & $3 / 6$ & Values & 1 \\
\hline $0 / 000$ & $0 / 290$ & $0 / 71$ & $3 / 63$ & Culture & 2 \\
\hline $0 / 043$ & $0 / 142$ & $0 / 84$ & $3 / 18$ & Software & 3 \\
\hline $0 / 003$ & $0 / 081$ & $1 / 06$ & $3 / 10$ & Hardware & 4 \\
\hline $0 / 000$ & $0 / 179$ & $0 / 49$ & $3 / 4$ & Leadership & 5 \\
\hline $0 / 001$ & $0 / 27$ & $0 / 99$ & $3 / 9$ & $\begin{array}{c}\text { Organizational } \\
\text { texture }\end{array}$ & 6 \\
\hline $0 / 012$ & $0 / 103$ & $1 / 26$ & $3 / 17$ & network & 7 \\
\hline
\end{tabular}

Finally, the Topsis method was used to prioritize the factors. Table 4 shows the proximity of each criterion to the ideal solution below:

The Topsis method is a multi-criteria decision-making method. The acronym Tapsis stands for preferred methods based on the similarity to the ideal solution. This model was proposed by Hwang \& Yoon (1981). In this method, the m option is evaluated by $\mathrm{n}$ index. The fundamental logic of this model defines the solution of the ideal (positive) and the solution of the negative ideal. The ideal (positive) solution is a solution that increases the profit criterion and reduces the cost criterion. The optimal option is the one that has the least distance from the ideal solution and at the same time the farthest distance from the negative ideal solution. In other words, in the ranking of options by the Topsis method, the options that most closely resemble the ideal solution are ranked higher.

Finally, the values extracted from the questionnaires are summarized in Table 5:

Table 5. Extracts from the questionnaire

\begin{tabular}{|c|c|c|c|c|c|c|c|}
\hline Total & $\begin{array}{c}\text { Very } \\
\text { good }\end{array}$ & Good & Medium & Weak & $\begin{array}{c}\text { Very } \\
\text { weak }\end{array}$ & Criterion & Column \\
\hline 63 & 17 & 20 & 11 & 5 & 10 & $\begin{array}{c}\text { Organizational } \\
\text { texture }\end{array}$ & 1 \\
\hline 63 & 21 & 19 & 9 & 11 & 3 & Values & 2 \\
\hline 63 & 20 & 17 & 15 & 7 & 4 & Culture & 3 \\
\hline 63 & 14 & 16 & 13 & 11 & 9 & Software & 4 \\
\hline 63 & 17 & 19 & 8 & 10 & 9 & Leadership & 5 \\
\hline 63 & 11 & 12 & 13 & 17 & 10 & Network & 6 \\
\hline 63 & 12 & 11 & 13 & 14 & 13 & hardware & 7 \\
\hline
\end{tabular}

In this type of non-scaling, each matrix element is divided into the sum squared of the elements of each column:

The uncaused value is option $i$ of the $\mathrm{j}$ index.

The data in Table 3 are displayed in Table 4 after normalization.

After disproportionate, the values related to each index, the relative importance of the indicators should be determined relative to each other. Which was performed by Shannon's (1993)entropy method. The main idea of this method is based on the fact that the higher the scatter in the values of an index, the more important that index is. 
Therefore, the following indexes are used to calculate the weights of the indicators:

$$
\begin{aligned}
& P_{i j}=\frac{a_{i j}}{\sum_{i=1}^{n} a_{i j}} ; \forall \mathrm{i}, \mathrm{j} \\
& k=\frac{1}{\ln (m)} \\
& E_{j}=-k \sum_{i=1}^{m}\left[p_{i j} \ln p_{i j}\right] ; \forall \mathbf{j} \\
& d_{j}=1-E_{j} ; \forall \mathbf{j}
\end{aligned}
$$

$\mathrm{m}$ is the number of factors.

$E_{j}$ shows entropy value of number $\mathrm{j}$ index.

The value of $d_{j}$ indicates the uncertainty or degree of deviation for index number $j$, and since the Shannon entropy method gives the highest weight to the index with the highest degree of deviation, we will have:

$$
w_{j}=\frac{d_{j}}{\sum_{j=1}^{n} d_{j}} ; \forall j
$$

Therefore, after the above calculations, the weight values of the criteria are given in Table 4:

Table 6 shows the proximity of each criterion to the ideal solution below: $E_{j}$ shows entropy value of number $\mathrm{j}$ index.

Table 6. Criterion weight matrix

\begin{tabular}{|c|c|c|c|c|c|}
\hline W5 & W4 & W3 & W2 & W1 & \\
\hline $0 / 114$ & $0 / 098$ & $0 / 093$ & $0 / 287$ & $0 / 406$ & Weight \\
\hline
\end{tabular}

Then, by determining the weighted matrix of criteria, a positive and negative ideal can be obtained for each indicator. For criteria that have a positive charge, the positive ideal is the largest value of that criterion and the negative ideal is the smallest value of that criterion. Therefore, the most appropriate ideal is equal to the combination of the largest values and the most inappropriate answer is the combination of the smallest values in each option.

The calculation of the scaleless matrix is obtained by the following formula:

$$
V=N \times W_{n \times n}
$$


Table 7. Matrix v

\begin{tabular}{ccccc}
\hline \multicolumn{5}{c}{ Matrix V } \\
\hline 0.0543 & 0.0077 & 0.0700 & 0.1138 & $\mathbf{0 . 1 4 6 6}$ \\
\hline 0.0163 & 0.0170 & 0.0573 & 0.1081 & $\mathbf{0 . 1 8 1 1}$ \\
\hline 0.0217 & 0.0108 & 0.0955 & 0.0967 & $\mathbf{0 . 1 7 2 5}$ \\
\hline 0.0489 & 0.0170 & 0.0828 & 0.0910 & $\mathbf{0 . 1 2 0 8}$ \\
\hline 0.0489 & 0.0155 & 0.0509 & 0.1081 & $\mathbf{0 . 1 4 6 6}$ \\
\hline 0.0543 & 0.0263 & 0.0828 & 0.0683 & $\mathbf{0 . 0 9 4 9}$ \\
\hline
\end{tabular}

The resulting product is a disproportionate balanced matrix $(\mathrm{V})$.

The ideal positive solution:

The largest value for positive indicators and the smallest value for negative indicators. In other words, we make up the best values for each index. $\left(V_{j}^{+}\right)$

Negative Ideal Solutions:

The largest value for negative indices and the smallest value for positive indices. In other words, we make up the worst values for each index. $\left(V_{j}^{-}\right)$

$$
\begin{aligned}
V_{j}^{+} & =\left[\max v_{i 1}, \max v_{i 2}, \max v_{i 3}, \max v_{i 4}, \max v_{i 5}\right] \\
V_{j}^{-} & =\left[\min v_{i 1}, \min v_{i 2}, \min v_{i 3}, \min v_{i 4}, \min v_{i 5}\right]
\end{aligned}
$$

Which equates to:

\begin{tabular}{cccccc}
\hline $\mathbf{v}+$ & $\mathbf{0} / \mathbf{1 8 1 1}$ & $\mathbf{0 / 1 1 3 8}$ & $\mathbf{0 / 0 9 5 5}$ & $\mathbf{0 / 0 2 6 3}$ & $\mathbf{0 / 0 7 0 6}$ \\
\hline $\mathbf{v}-$ & 0.0950 & $0 / 0626$ & $0 / 0509$ & 0.0077 & $0 / 0163$ \\
\hline
\end{tabular}

As well as calculating the Euclidean distance of each option to positive and negative ideas:

$$
\begin{aligned}
& d_{i}^{+}=\sqrt{\sum_{j=1}^{n}\left(v_{i j}-v_{j}^{+}\right)^{2}}, \quad \mathrm{i}=1,2, \ldots, \mathrm{m} \\
& d_{i}^{-}=\sqrt{\sum_{j=1}^{n}\left(v_{i j}-v_{j}^{-}\right)^{2}}, \quad \mathrm{i}=1,2, \ldots, \mathrm{m}
\end{aligned}
$$

That $\mathrm{d}+$ is equal to:

\begin{tabular}{ccccccc}
\hline d7 & d6 & d5 & d4 & d3 & d2 & d1 \\
\hline $0 / 0940$ & $0 / 0997$ & $0 / 0616$ & $0 / 0699$ & $0 / 0547$ & $0 / 0673$ & $\mathbf{0 / 0 4 9 5}$ \\
\hline
\end{tabular}

And so d- is equal to:

$\begin{array}{lllllll}\text { d-7 } & d-6 & d-5 & d-4 & d-3 & d-2 & d-1\end{array}$




$\begin{array}{lllllll}0 / 0650 & 0 / 0532 & 0 / 0766 & 0 / 0603 & 0 / 0960 & 0 / 0982 & \mathbf{0} / \mathbf{0 8 4 3}\end{array}$

Then determine the relative proximity of an option to the ideal solution:

$$
C L_{i}^{*}=\frac{d_{i}^{-}}{d_{i}^{-}+d_{i}^{+}}
$$

Table 8. How close each criterion is to the ideal solution

\begin{tabular}{ccc}
\hline$C L_{i}^{*}$ & factors & colemn \\
\hline $0 / 630$ & organizational texture & $\mathbf{1}$ \\
\hline $0 / 593$ & values & $\mathbf{2}$ \\
\hline $0 / 637$ & culture & $\mathbf{3}$ \\
\hline $0 / 463$ & software & $\mathbf{4}$ \\
\hline $0 / 554$ & leadership & $\mathbf{5}$ \\
\hline $0 / 348$ & network & $\mathbf{6}$ \\
\hline $0 / 409$ & hardware & $\mathbf{7}$ \\
\hline
\end{tabular}

The table above shows the relative proximity of each option to the ideal solution. The value is between zero and one. The closer it is to a value, the closer the solution is to the ideal answer. Now, according to the obtained values, the factors are arranged in descending order and the priority of the effectiveness of each index is determined:

Table 9. Arrangement and importance of priority for each factor

\begin{tabular}{cc}
\hline Factors & Column \\
\hline Culture & $\mathbf{1}$ \\
\hline Organizational texture & $\mathbf{2}$ \\
\hline Values & $\mathbf{3}$ \\
\hline Leadership & $\mathbf{4}$ \\
\hline Software & $\mathbf{5}$ \\
\hline Hardware & $\mathbf{6}$ \\
\hline Network & $\mathbf{7}$ \\
\hline
\end{tabular}

Based on the results obtained among the seven influential parameters, one of the vital and important factors of using the institutional factor of culture and then the factors of organizational context and values are the most important criteria influencing this characteristic. It should also be noted that the choice of the knowledge management process is not an accidental phenomenon. Rather, it is a science that requires a thorough understanding of tools, programs, and goals based on specific knowledge. However, close and thorough supervision of the relevant authorities in the field of knowledge management and the existence of the necessary guarantees can lead to the observance of many positive and effective cases.

\section{Conclusion and discussion}

In this study, the important and influential factors on the effectiveness of knowledge management in the design offices of a product-oriented organization were examined. Because the infrastructure and knowledge management institutions have been considered as the backbone of knowledge management, and almost all organizations that have successfully used knowledge management to the need and importance of supporting infrastructure for successful deployment the knowledge management system is well aware. Therefore, the fact that the establishment of knowledge management in the organization requires the existence of institutional factors and strong and appropriate infrastructure is confirmed. If organizations want to manage knowledge as an organizational asset, they must provide the factors mentioned in this research appropriately. Because the necessary bases and infrastructures for the 
establishment and use of the new knowledge management system are important in the sense that the implementation of this system, regardless of the platforms and their strengths and weaknesses, will often fail.

The results of the analysis of research data show that the institutional factors affecting the establishment of knowledge management system in the mentioned place can be mentioned values, culture, organizational context and leadership. Also, the infrastructures affecting the establishment of knowledge management system can be identified in the form of three general infrastructures of software, hardware and network, the most important of which have been identified as priorities affecting the establishment of knowledge management system in the organization.

In total, it can be said that culture, organizational structure, values and information technology (equipment) are important components that have been confirmed in this research as knowledge management factors. Therefore, the implementation of a knowledge management system in the design office requires attention to these elements, with the appropriate culture, structure and organizational structure and the use of information technology tools can achieve this.

Data analysis shows the following important points:

- The institutional factor of culture has the greatest impact and prioritization on the effectiveness of knowledge management (with a coefficient of 0.613 ). Therefore, the organization should prioritize culture in its program. The high level of culture establishment compared to other components can be due to proper management, employees' sense of belonging and friendly cooperation of employees with each other, group work, making the right decisions, and so on. So that planners and decisionmakers have been able to implement the application of culture in the establishment of a knowledge management system to some extent. Also, the research results showed that the more organizational culture, the better the knowledge management will be in a better position.

- The institutional factor of organizational structure has the second priority on the effectiveness of knowledge management (with a coefficient of 0.584).

- The institutional factor of values has the third priority on the effectiveness of knowledge management (with a coefficient of 0.530).

- Also, the findings of this study have shown that the rate of establishment of the leadership component compared to other components is at a moderate level. This can be due to the managers' lack of interest in staffing and lack of knowledge about the importance of knowledge management, hierarchical and inflexible structure in management, lack of trust and support of senior managers in management activities and programs. Improper knowledge and leadership styles. Explaining that the lack of clear criteria for evaluating employee performance and failure to solve organizational problems of employees by the leadership is the most important problem that has been raised by the respondents regarding the component of knowledge management leadership system.

Since neglecting the performance of employees, especially in the field of increasing knowledge and distribution of knowledge and not evaluating them, can destroy their motivation in this regard. Therefore, it is better to evaluate the performance of employees in the field of knowledge management annually and with clear indexes.

- Based on the research findings, the component of information technology (software, hardware and network) in the era when technology has significant progress in all areas, is at a low level from the perspective of employees; therefore, it is suggested that the planners and decision-makers of the organization provide new resources and equipment, including computers, and the possibility of quick and easy access to the Internet and domestic and foreign scientific journals for acquiring, creating and disseminating knowledge, staff and learn the right technology tools.

- In general, according to the total scores obtained by the organization and the scores obtained from each factor, it can be said that the organization is not in a good position and if the strategy is to be knowledge-based, it should be a knowledge management project. At the organizational level, it was implemented systematically and systematically, and by pursuing it, it led the organization to the excellence of knowledge. Finally, with an overview of the findings of this study, it can be concluded that organizational structure, culture and values, above average, can be established in the productoriented organization and policies and management. 
The present research was conducted on the design offices of a product-oriented organization in Tehran. Further research on individuals from different production and service organizations can help validate the findings of this study. It is suggested that the organization, while promoting investment in technology infrastructure, also consider their knowledge use. In future research, it is suggested that the role of intellectual property as an institutional variable in the implementation and establishment of knowledge management and the factors affecting the protection of the interests of small stakeholders in the implementation of knowledge management in organizations should be considered.

\section{References}

Akhavan, P., Hosnavi, R., \& Sanjaghi, M. E. (2009). Identification of knowledge management critical success factors in Iranian academic research centers. Education, Business and Society: Contemporary Middle Eastern Issues.

Akhavan, P., Jafari, M., \& Akhtari, M. (2011). Exploration of knowledge acquisition techniques in tunnel industry: The case study of iran tunnel association. International journal of business and management, 6(8), 245-255.

Allard, S., \& Holsapple, C. W. (2002). Knowledge management as a key for e-business competitiveness: from the knowledge chain to KM Audits. Journal of Computer Information Systems, 42(5), 19-25.

Argote, L. (2012). Organizational learning: Creating, retaining and transferring knowledge. Springer Science \& Business Media.

Astorga-Vargas, M. A., Flores-Rios, B. L., Licea-Sandoval, G., \& Gonzalez-Navarro, F. F. (2017). Explicit and tacit knowledge conversion effects, in software engineering undergraduate students. Knowledge Management Research \& Practice, 15(3), 336-345.

Bigliardi, B., \& Galati, F. (2013). Innovation trends in the food industry: The case of functional foods. Trends in Food Science \& Technology, 31(2), 118-129.

Commoner, B. (2020). The closing circle: nature, man, and technology. Courier Dover Publications.

Dalkir, K. (2005). Knowledge management in theory \& practice. Elsevier butterworth- heinemann.

Dávideková, M., \& Hvorecký, J. (2016). Collaboration tools for virtual teams in terms of the SECI model. Paper presented at the International Conference on Interactive Collaborative Learning.

Dubé, L., Bourhis, A., Jacob, R., \& Koohang, A. (2006). Towards a typology of virtual communities of practice. Interdisciplinary Journal of Information, Knowledge \& Management, 1.

Girard, J., \& Girard, J. (2015). Defining knowledge management: Toward an applied compendium. Online Journal of Applied Knowledge Management, 3(1), 1-20.

Gopta, B., Lyer, L. s. m et, al. (2010). Knowledge Management: practices and challenges. Industrial management \& pata system, 100(1), 17-21.

Hassanali, A., Giberti, F., Cuny, J., Kühne, T. D., \& Parrinello, M. (2013). Proton transfer through the water gossamer. Proceedings of the National Academy of Sciences, 110(34), 13723-13728.

Hoffman. , Hoelscher, m. L., sheriff-k.(2005). Social capital, Knowledge Management and sustained a superior performance. Journal of Knowledge Management, 9(3).93-100.

Holsapple, C. W., \& Joshi, K. D. (2000). An investigation of factors that influence the management of knowledge in organizations. The Journal of Strategic Information Systems, 9(2-3), 235-261.

Holsapple, M. P., West, L. J., \& Landreth, K. S. (2003). Species comparison of anatomical and functional immune system development. Birth Defects Research Part B: Developmental and Reproductive Toxicology, 68(4), 321-334.

Hwang, C. L., Yoon, K. (1981). Multiple attributes decision making methods and applications. Heidelberg: Springer.

Intezari, A., Taskin, N., \& Pauleen, D. J. (2017). Looking beyond knowledge sharing: an integrative approach to knowledge management culture. Journal of Knowledge Management.

Jafari, M., Fesharaki, M. N., \& Akhavan, P. (2007). Establishing an integrated KM system in Iran aerospace industries organization. Journal of knowledge management, 11(1), 127-142.

Keenan, J. M., Hill, T., \& Gumber, A. (2018). Climate gentrification: from theory to empiricism in Miami-Dade County, Florida. Environmental Research Letters, 13(5), 054001.

Keenan, J. M., Hill, T., \& Gumber, A. (2018). Climate gentrification: from theory to empiricism in Miami-Dade County, Florida. Environmental Research Letters, 13(5), 054001. 
Last, C. (2017). Big historical foundations for deep future speculations: cosmic evolution, atechnogenesis, and technocultural civilization. Foundations of Science, 22(1), 39-124.

Lewrick, M., Link, P., \& Leifer, L. (2018). The design thinking playbook: Mindful digital transformation of teams, products, services, businesses and ecosystems. John Wiley \& Sons.

Martenson. M. (2000). A critical review of knowledge management as a management toll. Journal of Knowledge Management, 4(3),214.

Meyer, Bertolt. Sugiyama, Kozo. (2007). The concept of knowledge in KM: a dimensional model. Journal of Knowledge Management. VII(NI), 17-35,

Milakovich, M. E. (2012). Digital governance: New technologies for improving public service and participation. Routledge.

Mohamed, M., Stankosky, M., \& Murray, A. (2006). Knowledge management and information technology: can they work in perfect harmony?. Journal of knowledge management.

Nonaka, I., \& Konno, N. (1998). The concept of "Ba": Building a foundation for knowledge creation. California management review, 40(3), 40-54.

Nonaka, L., Takeuchi, H., \& Umemoto, K. (1996). A theory of organizational knowledge creation. International Journal of Technology Management, 11(7-8), 833-845.

Powell, B. J., Waltz, T. J., Chinman, M. J., Damschroder, L. J., Smith, J. L., Matthieu, M. M., ... \& Kirchner, J. E. (2015). A refined compilation of implementation strategies: results from the Expert Recommendations for Implementing Change (ERIC) project. Implementation Science, $10(1), 1-14$.

Probst, G., Raub, S., \& Romhardt, K. (2003). Bausteine des Wissensmanagements. In Wissen managen (pp. 25-33). Gabler Verlag.

Sánchez, N. F. (2013). Trastornos de conducta y redes sociales en Internet. Salud mental, 36(6), 521 527.

Shannon, C. E. (1993). Claude elwood shannon: Collected papers. IEEE press.

Siliv, Richard. Cuganesan, Suresh. (2006). Investigative the Management of Knowledge for competitive advantage. Journal of Intelligence Capital. 7(3), 306-323.

Sugurmaran., \& Bose. (2003). Application of knowledge management techniques in customer relationship management. Journal of Knowledge and Process Management, 10(1), 3-17.

Verhagen, E., Deléglise, S., Weis, S., Schliesser, A., \& Kippenberg, T. J. (2012). Quantum-coherent coupling of a mechanical oscillator to an optical cavity mode. Nature, 482(7383), 63-67.

Wiig, K. M. (1997). Knowledge management: an introduction and perspective. Journal of knowledge Management.

Williams, R. L., \& Bukowitz, W. R. (2001). The yin and yang of intellectual capital management: The impact of ownership on realizing value from intellectual capital. Journal of Intellectual Capital. 